\title{
A study on the saturation degree dependency of the seismic behaviour of retaining walls
}

\author{
M.J. Momeni ${ }^{1}$ G. Habibagahiia ${ }^{2 a}$. Nikooee ${ }^{3}$ \\ ${ }^{1}$ Graduate student, Department of Civil and Environmental Engineering, School of Engineering, Shiraz University, Shiraz, Iran \\ ${ }^{2}$ Professor, Department of Civil and Environmental Engineering, School of Engineering, Shiraz University, Shiraz, Iran \\ ${ }^{3}$ Assistant Professor, Department of Civil and Environmental Engineering, School of Engineering, Shiraz University, Shiraz, Iran
}

\begin{abstract}
Retaining walls are important geotechnical structures that are often used in soil slopes and trenches to bring ground surface at appropriate level for the construction of roads, highways and buildings. It is common practice to assume that the soil behind a retaining structure is either fully saturated or completely dry. However, for the case the soil is partially saturated, mechanical behaviour of the soil above the water table is different than that of the dry soil. Thus, it is necessary to investigate the effect of the variations of degree of saturation on lateral pressure behind retaining walls. In this research, the seismic behaviour of unsaturated soils behind a retaining structure is analysed. A finite difference code was employed to conduct the necessary analyses and a series of equivalent linear analyses is performed to reveal the effect of the degree of saturation on the general response of the retaining structures. The required functions for unsaturated zone were defined and implemented in the code. For this purpose, a soil water retention function was employed and the soil shear modulus is assumed to vary with the mean effective stress for both saturated and unsaturated zones which naturally introduces the required hydro-mechanical coupling in unsaturated and saturated zone. The results of the analyses compared to the conventional methods which does not include the unsaturated mechanical properties, indicate that in the unsaturated state, the increase in the effective stress, and hence, the shear modulus considerably affects the seismic forces on the retaining wall.
\end{abstract}

\section{Introduction}

Retaining Walls are important geotechnical structures that are often used to create desired change in ground elevation in slopes and trenches. In analysis of the most of lateral pressure problems, such as retaining walls, slope stability, and shallow foundations, it is assumed that the soil is either completely dry or fully saturated. But in reality, soil is partially saturated and has different shear strength as compared to dry soil due to the presence of matric suction.

Matric suction increases contact forces between grains and makes unsaturated soils stronger than dry soils [1]. It has been a common practice by geotechnical practitioners not to consider the partial saturation effect on shear strength which makes the design conservative. However considering the effect of partial saturation can decreases construction costs significantly. Furthermore, the effects of such consideration on the behavior of earth structures on various conditions should be, carefully, taken into account one of which is their seismic behavior. Usually geotechnical engineers deal with risky earth structures, such as unstable slopes. In such cases, a complete analysis of existing stresses that includes properties of

\footnotetext{
${ }^{\mathrm{a}}$ Corresponding author: habibg@shirazu.ac.ir
}

partially saturated regions located above water level is critical to identify instability reasons [2].

In order to determine partial saturation effects on stability of earth structures, methodologies should be expanded to analyze failure conditions in partially saturated soils. To date, there has not been much work on this issue. In particular, the seismic behavior of retaining walls taking into account the possible presence of adjacent unsaturated regions have not been thoroughly looked in to. The objective of current research is, therefore, to study the effects of the variation of the degree of saturation of soils on the effective stress, and shear modulus $(\mathrm{G})$ of soil and accordingly the seismic behavior of unsaturated retaining wall.

\section{Dynamic analysis methodology}

\subsection{Equivalent Linear Method}

In this study, the Equivalent Linear method (E.L.) was used. E.L. starts a dynamic analysis with specified soil stiffness. In the first stage, FLAC processes the entire earthquake record and identifies the peak shear strain at each Gauss numerical integration point in each element. 
The shear modulus is then modified according to a specified $G$ reduction function and the process is repeated. This iterative procedure continues until the required $\mathrm{G}$ modifications are within a specified tolerance $[3,4]$. In each iteration, the values of damping ratio and the shear modulus were updated based on the current values of the confining pressure, the effective stress state of the element and the maximum shear strain in that iteration.

\section{2 seismic analysis of unsaturated soils}

Due to the presence of matric suction, the heterogeneity induced by the variation of the degree of saturation in different elements and different state of the effective stress than that of the fully saturated soil or dry case, careful consideration of the hydromechanical coupling is necessary in the seismic analysis of unsaturated soils. Hereafter, the parameters and variables, and the required steps for such analysis are explained (sections 2.2.1 to 2.2.4).

\subsubsection{Formulating the effective stress in unsaturated elements}

Effective stress in unsaturated soils was calculated using the following equation (Bishop 1959):

$$
\sigma^{\prime}=\sigma-u_{a}+\chi\left(u_{a}-u_{w}\right)
$$

Where:

$\sigma$ denotes total stress, $\chi$ is effective stress parameter, the term $\left(u_{a}-u_{w}\right)$ denotes soil matric suction. $u_{a}$ specifies air pressure and $u_{w}$ is pore water pressure.

There are various formulations for the effective stress parameter. As discussed by Nikooee et al. (2013) and Pereira et al. (2010), degree of saturation is not a good candidate for the effective stress parameter, especially in fine grained soils [5, 6]. Recently $\mathrm{Lu}$ et al. (2010) suggested the use of effective degree of saturation for the effective stress parameter to account for the fact that the immobile water does not contribute to the mechanical behaviour of unsaturated soils [7]. Furthermore, Oh and Lu (2014) have shown that the use of effective degree of saturation results in a reasonable approximation of suction stress under different hydraulic and mechanical states [8]. Therefore, in this study the effective stress parameter was assumed to be effective degree of saturation.

$$
\chi=\frac{S_{r}-S_{r 0}}{1-S_{r 0}}
$$

Where $S_{r}$ is degree of saturation and $S_{r 0}$ is the residual degree of saturation.

\subsubsection{Calculation of the shear modulus in unsaturated region}

During dynamic or seismic excitation, the soil sample tends to soften in response to shear strain cycle. This softening is often expressed as a ratio of maximum shear modulus $\mathrm{G}_{\max }$. Equation 3 was therefore used to estimate $\mathrm{G} / \mathrm{G}_{\max }[4,9]$. In this equation, plasticity index and effective confining pressure are two main variables. Effective confining pressure was calculated by means of equation 1 for vertical effective stress. The shear modulus ratio was calculated as follows:

$$
\begin{gathered}
\frac{G}{G_{\max }}=K(\gamma, P I)\left(\sigma_{m}^{\prime}\right)^{m(\gamma, P I)-m_{0}} \\
K(\gamma, P I)=0.5\left\{1+\tanh \left[\ln \left(\frac{0.000102+n(P I)}{\gamma}\right)^{0.492}\right]\right\} \\
m(\gamma, P I)-m_{0}=0.272\left\{1-\tanh \left[\ln \left(\frac{0.000556}{\gamma}\right)^{0.4}\right]\right\} \\
\operatorname{xexp}\left(-0.0145 P I^{1.3}\right)
\end{gathered}
$$

Where the sub-function $n(P I)$ is estimated using equations 6 to 9:

$$
\begin{array}{cc}
n(P I)=0.0 & \text { for } P I=0 \\
n(P I)=3.37 \times 10^{-6} P I^{1.404} & \text { for } 0<P I<15 \\
n(P I)=7.00 \times 10^{-7} P I^{1.976} & \text { for } 15<P I<70 \\
n(P I)=2.70 \times 10^{-5} P I^{1.115} & \text { for } P I>70
\end{array}
$$

$\gamma$ is the maximum shear strain in each zone during earthquake which is multiplied by 0.65 to be converted to equivalent shear strain. In equation 3 , mean effective stress $\left(\sigma_{m}^{\prime}\right)$ should be in $\mathrm{kPa}$. Maximum shear modulus is a function of confining stress as follows [4]:

$$
G_{\max }=21.7 \times P_{a} \times K_{2, \max } \times\left[\frac{\sigma_{m}^{\prime}}{P_{a}}\right]^{0.5}
$$

In this equation $P_{a}$ is the atmospheric pressure, $K_{2, \max }$ is a constant which is defined using relative density and $\sigma_{m}^{\prime}$ is the mean effective stress which is calculated using equation 1 in unsaturated case:

$$
\begin{gathered}
\sigma_{x x}^{\prime}=\sigma_{x x}-u_{a}+\chi\left(u_{a}-u_{w}\right) \\
\sigma_{y y}^{\prime}=\sigma_{y y}-u_{a}+\chi\left(u_{a}-u_{w}\right) \\
\sigma_{z z}^{\prime}=\sigma_{z z}-u_{a}+\chi\left(u_{a}-u_{w}\right) \\
\sigma_{m}^{\prime}=\frac{\sigma_{y y}^{\prime}+\sigma_{x x}^{\prime}+\sigma_{z z}^{\prime}}{3}
\end{gathered}
$$


Parameters and variables used in equations 11 to 14 are as follows:

$\sigma_{y y}^{\prime}=$ Vertical effective stress

$\sigma_{x x}^{\prime}$ and $\sigma_{z z}^{\prime}=$ Horizontal effective stresses

$\chi=$ Effective stress parameter

$u_{a}=$ Air pressure

\subsubsection{Determining damping ratio}

Damping ratio of soil is also effected by cycle shear strain and should be modified in each dynamic analysis in equivalent linear method. This was done by employing the following damping ratio function (equation 15). Variables in the equation are plasticity index, ratio of shear modulus to maximum shear modulus, and therefore, it depends indirectly also on the mean effective stress:

$$
\xi=0.333 \frac{1+\exp \left(-0.0145 P I^{1.3}\right)}{2}\left[0.586\left(\frac{G}{G_{\max }}\right)^{2}-1.547 \frac{G}{G_{\max }}+1\right]
$$

\subsubsection{Unsaturated shear strength}

The shear strength formulation employs Bishop effective stress equation for the effective stress. It reads as follows:

$$
\tau=c^{\prime}+\left(\sigma_{n}-u_{a}\right) \tan \varphi^{\prime}+\chi\left(u_{a}-u_{w}\right) \tan \varphi^{\prime}
$$

$C^{\prime}=$ Effective cohesion

$\sigma_{n}=$ Total vertical stress on failure plane

$\varphi^{\prime}=$ Internal friction angle of soil

\section{Statement of problem and modelling}

In this study, the finite difference code FLAC was utilized for creating the model and analyzing the unsaturated seismic behavior of the retaining wall. The model was consisted of 3000 elements. A combination of mesh refinement around the retaining wall and coarser elements far from the retaining wall was considered. This way the computational cost can be kept low without considerable loss in precision. (Figure 1).

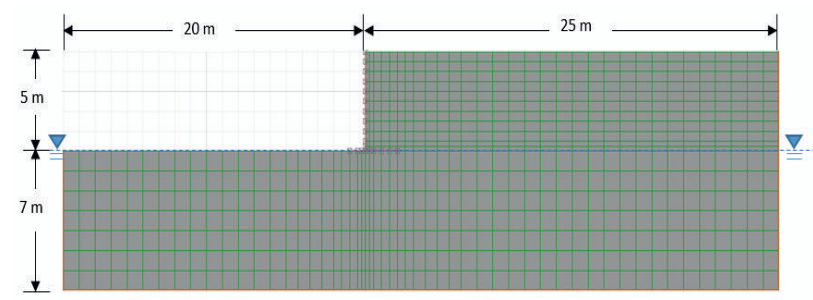

Figure 1. Geometry and dimensions of the model

Elastic beam elements were used to model the concrete retaining wall. Four parameters were required: crosssectional area $\left(0.5 \mathrm{~m}^{2}\right)$, mass density, elastic modulus, and second moment of area $\left(0.004 \mathrm{~m}^{4}\right)$. Table 1 shows properties of retaining wall materials and the soil beneath foundation. For modeling the interaction between the concrete retaining wall and soil, interface elements were used that have four parameters $\left(\mathrm{S}, \mathrm{T}, k_{n}, k_{S}\right)$, where, $\mathrm{S}$ is a function of the interface friction angle $\left(\delta=\frac{2}{3} \varphi=24^{0}\right), \varphi$ is the friction angle of backfill soil. $\mathrm{T}$ specifies tensile strength and has been set to zero (i.e., cohesionless soil). $k_{n}$ and $k_{s}$ are normal and shear stiffness, respectively [10]. As a rule of thumb, $k_{n}$ and $k_{s}$ should be set to 10 times the equivalent stiffness of the neighboring zone [2], i.e., $10 \max \left[\frac{K+\frac{4}{3} G_{\max }}{\Delta y_{\min }}\right]$ where $\mathrm{K}$ and $G_{\max }$ are the bulk and small strain shear moduli, respectively, and $\Delta y_{\min }$ is the smallest width of the zone (elements) perpendicular to the interface. Water level is in depth of 5 meters from ground surface(Figure 1), above which and behind the wall(due to capillary rise), there is an unsaturated region and the unsaturated properties have been assigned to the elements. Mohr-Coulomb criteria is used to simulate strain-stress behavior of soil. Element are $2 \mathrm{D}$ four nodes type. Dimension of elements are chosen so that the element are either rectangular or square shaped. For accurate representation of wave transmission in the numerical models, it is suggested to use element dimensions $(\Delta L)$ be less than $1 / 8$ to $1 / 10$ of $\lambda$ of the maximum entering wave frequency where $\lambda$ is the wavelength. Based on maximum wavelength considered in this study, maximum allowable dimensions for elements were $1.5 \mathrm{~m}$. In order to reduce the boundary effects, the lateral boundaries of model should be in distant from the wall. For this purpose, a distance of 4-5 times of wall height was chosen from each side of the wall.

Table 1. Properties of soil layers and wall

\begin{tabular}{|c|c|c|c|c|}
\hline & $\begin{array}{c}\text { Density } \\
\left(\mathrm{Kg} / \mathrm{m}^{3}\right)\end{array}$ & $\begin{array}{c}\text { Poison's } \\
\text { Ratio }\end{array}$ & $\begin{array}{c}\text { Friction } \\
\text { Angle } \\
(\text { Degree })\end{array}$ & $\begin{array}{c}\text { Shear } \\
\text { Modulus } \\
(\mathrm{kPa})\end{array}$ \\
\hline $\begin{array}{c}\text { Concrete } \\
\text { Retaining } \\
\text { Wall }\end{array}$ & 2300 & 0.2 & - & 10700000 \\
\hline $\begin{array}{c}\text { Backfill } \\
\text { Soil }\end{array}$ & 1600 & 0.3 & 35 & 13000 \\
\hline $\begin{array}{c}\text { Foundation } \\
\text { Soil }\end{array}$ & 1750 & 0.26 & 40 & 36000 \\
\hline
\end{tabular}

Table 2. Van Genuchten parameters

\begin{tabular}{|c|c|}
\hline Van Genuchten parameters & value \\
\hline$a_{v g}$ & 0.75 \\
\hline$n_{v g}$ & 1.88 \\
\hline$m_{v g}$ & 0.23 \\
\hline$w_{r}(\%)$ & 0.2 \\
\hline
\end{tabular}

In current study, the lateral boundaries of the main grid are coupled to the free-field grid by viscous dashpots to simulate a quiet boundary. The lower boundary is fixed (no displacement is allowed in vertical and horizontal direction). The displacement of soil elements adjacent to the boundary of wall is controlled by wall (compatibility condition). 
The wall backfill soil is sand with dry density of 1600 $\mathrm{kg} / \mathrm{m}^{3}$ and foundation soil is compacted sand and gravel mixture with dry density of $1750 \mathrm{~kg} / \mathrm{m}^{3}$ (designated as GW based on the unified soil classification, 70\% Gravel and $30 \%$ sand). Density and elasticity parameters of the aforementioned soils are reported in Table 1. It is noteworthy that the considered input parameters are obtained from soilvision database. The backfill soil is soil no. 10700 and the soil under foundation is soil no. 18719 in this database. The retention properties of the considered soil types have been reported in table 2.Modeling the retaining wall was performed utilizing the elastic beam element and through a finite difference code. In order to consider interaction between soil and structure, the contact surface between soil and the wall was introduced to the model using boundary elements. Friction angle was considered two third of the internal friction angle of the backfill soil. As common, Rayleigh damping of 0.05 was selected for initial analysis in order to create dynamic model. Two scenarios for modeling the backfill soil were considered. In the first modeling scenario, the backfill soil was considered dry. In the second case, the capillary rise (the unsaturated region behind the retaining wall) was taken into account. As the soil under foundation has been considered saturated in our models, the two modeling scenarios are called sat-dry and sat-unsat hereafter.

The AEROPUETRTO MEXICALI 1979 earthquake record was applied to the bottom boundary of the model as an accelerogram (Figure 2). Maximum earthquake acceleration is reduced (the record is therefore scaled) to the maximum acceleration for Shiraz (Iran) which is $0.3 \mathrm{~g}$.

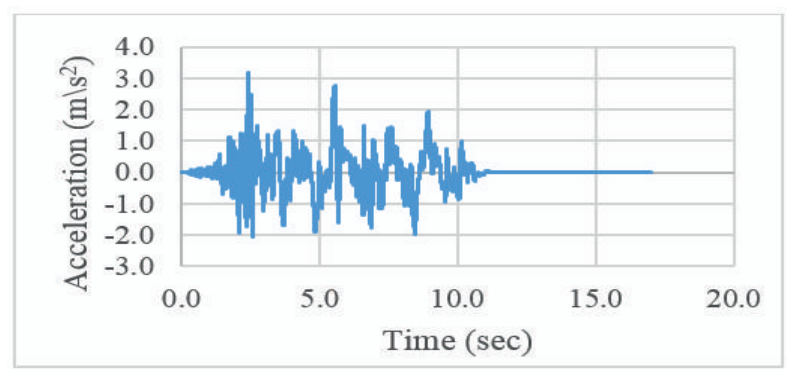

Figure 2. Input accelerogram

\section{Results and discussion}

\subsection{Effect of unsaturated zone on mean effective stress}

Figure 3 presents the comparison of mean effective stress $\sigma_{m}^{\prime}$ in dry and unsaturated modeling scenarios considered for the backfill (to recall for the derivation of the mean effective stress, please see equations 11 to 14).



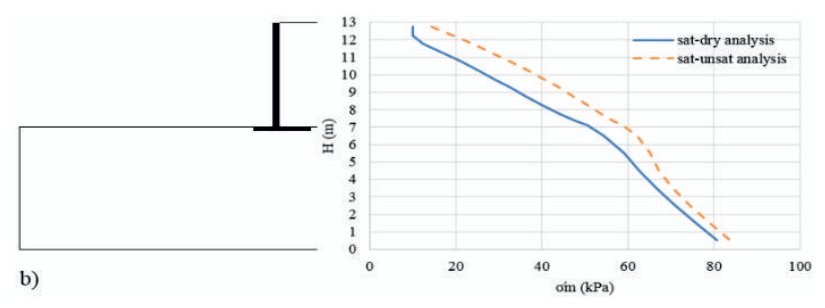

Figure 3. Mean effective stress versus height in dry and unsaturated backfill conditions (a. Wall $=5 \mathrm{~m}, \mathrm{~b}$. Wall $=6 \mathrm{~m}$ )

As expected, the mean effective stress will increase with depth since the vertical effective stress increases with depth (equation 14). As it will be discussed in next section, the mean effective stress and its variation with the degree of saturation play an important role in seismic behavior of earth structures.

\subsection{Effect of unsaturated zone on shear modulus}

In this section, the presence of negative pore water pressure in unsaturated region and its effects on the shear modulus of soil is taken into account. The results are then compared to the condition where the backfill soil is dry (Figure 4).

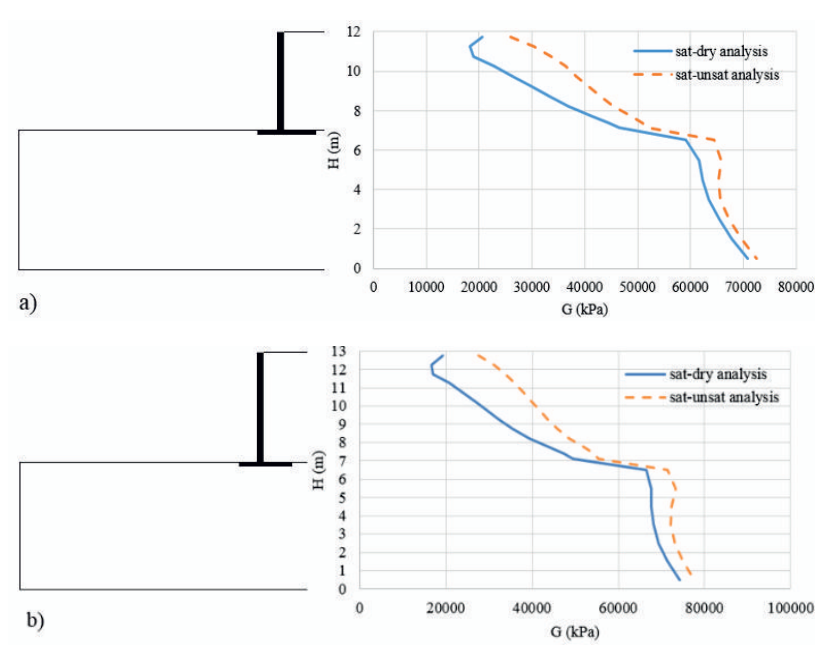

Figure 4. Shear modulus versus height in dry and unsaturated backfill conditions (a. Wall $=5 \mathrm{~m}, \mathrm{~b}$. Wall $=6 \mathrm{~m}$ )

As equation 3 and equation 10 indicate, shear modulus and maximum shear modulus have direct relationship with the effective stress level. It could, therefore, be concluded that variation of shear modulus in dry and unsaturated soil is similar to the variation in mean effective stress for these two conditions which is confirmed by Figure 3. Larger shear modulus resulted from presence of suction will inevitably result in larger soil stiffness which has considerable impact on the seismic behavior of the retaining wall.

\subsection{Effect of unsaturated zone on resultant force applied on the wall and its point of effect}


The lateral earth force from earthquake at each nodal point on the wall was determined and the resultant total lateral force was then calculated. The variation of resultant force during the earthquake is illustrated in Figure 5. The resultant force was calculated using the following formulae:

$$
\begin{gathered}
F_{i, j}^{\text {top }}=\frac{1}{2} \cdot h_{i} \cdot \sigma_{i, j}^{\text {top }}=\frac{1}{2} \cdot h_{i} \cdot \sigma_{i, j} \\
F_{i, j}^{\text {bottom }}=\frac{1}{2} \cdot h_{i} \cdot \sigma_{i, j}^{\text {bottom }}=\frac{1}{2} \cdot h_{i} \cdot \sigma_{i, j} \\
P_{j}=\sum_{i}\left(F_{i, j}^{t o p}+F_{i, j}^{b o t t o m}\right)=\sum_{i} \sigma_{i, j} \cdot h_{i}
\end{gathered}
$$

As it is shown in Figure 5, the resultant force applied on the wall is fluctuating during the earthquake in both dry and unsaturated conditions. This is due to variation in horizontal stresses during the earthquake. From this figure it is obvious that the resultant force in unsaturated condition is less than dry condition. The increase in soil shear strength due to matric suction is the main reason for this phenomenon. In both conditions, the maximum resultant force occurs at the same time $(\mathrm{t}=5.7 \mathrm{sec})$.
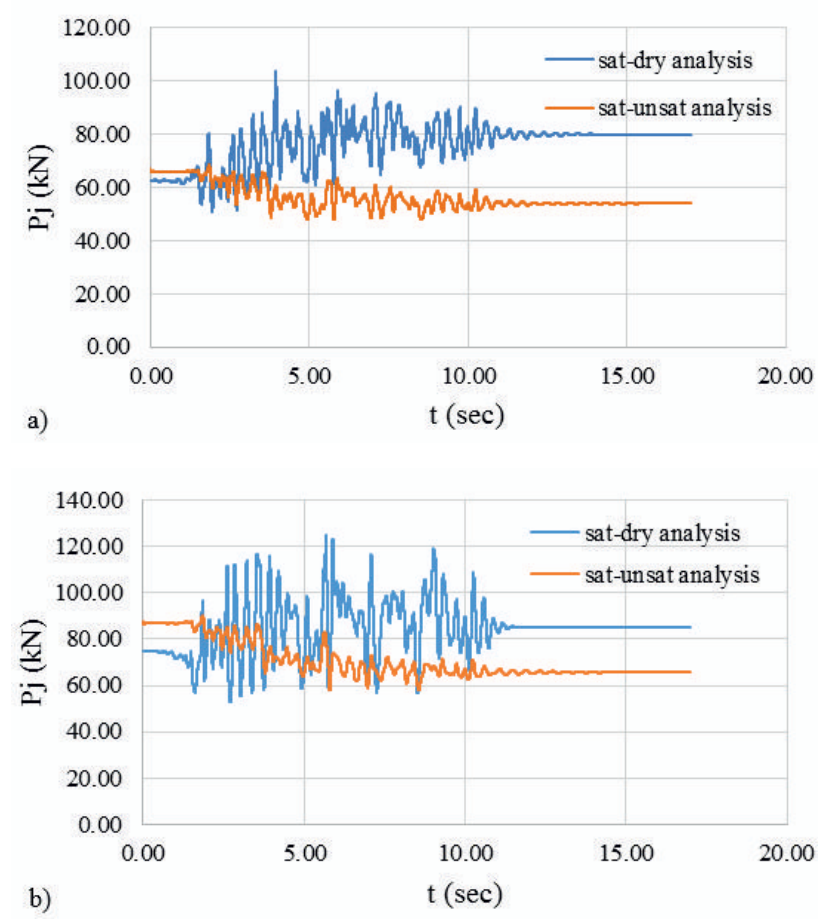

Figure 5. Variation of resultant force applied on the wall during earthquake in dry and unsaturated backfill conditions. (a. Wall $=5 \mathrm{~m}, \mathrm{~b}$. Wall $=6 \mathrm{~m}$ )

The point of application of the resultant dynamic forces on the wall (Figure 6), is calculated using the following equation.

$$
Y_{j}=\frac{\sum_{i} h_{i} \cdot \sigma_{i, j} \cdot y_{i}}{\sum_{i} h_{i} \cdot \sigma_{i, j}}
$$

Where $Y_{j}$ is the vertical distance from base of the retaining wall to the point of application of total resultant force in time $\mathrm{j}$, and $\mathrm{y}_{\mathrm{i}}$ is the vertical distance from base of the retaining wall to the center of element $i$.
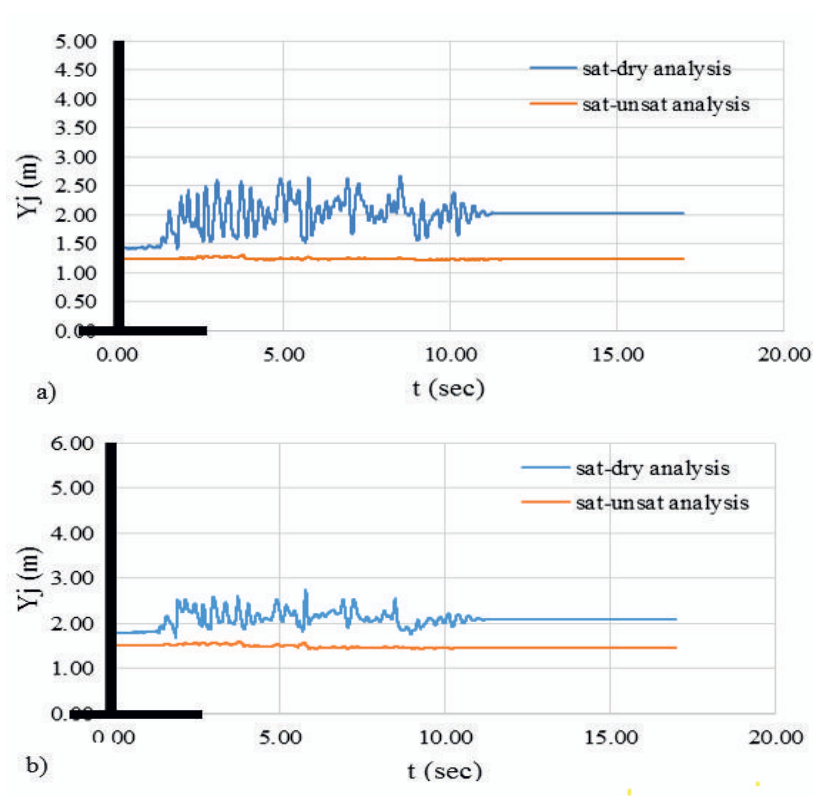

Figure 6. The point of effect of resultant dynamic forces on the wall. $($ a. Wall $=5 \mathrm{~m}, \mathrm{~b}$. Wall $=6 \mathrm{~m})$

\subsection{Effect of negative pore water pressure on earth pressure coefficient of soil}

Horizontal pressure coefficients at any time can be calculated from applied horizontal forces using the following equation. $\mathrm{K}_{\mathrm{vj}}$ is vertical earthquake coefficient and is assumed to be zero in this study.

$$
K_{F L A C}=\frac{2 P_{F L A C}}{\gamma_{t} H^{2}\left(1-k_{v j}\right)}
$$

Furthermore, lateral pressure coefficient under seismic load was calculated using Mononobe-Okabe method. The values of horizontal inertial coefficient, $k_{h}$, at the middle of the backfill portion of the structural wedge (expressed in terms of gravitational acceleration) were computed during the FLAC analysis (Figure 7).

In order to compare the results of numerical simulations for dry and unsaturated analyses with those from Mononobe-Okabe equation, they are all plotted on the same graph. These graphs are plotted for walls with heights of 5 and 6 meters, respectively (Figures 8 and 9). In these graphs lateral earth pressure coefficient $\mathrm{K}$ obtained from numerical simulation as well as values from Mononobe-Okabe equation have been depicted versus coefficient of horizontal earthquake acceleration.

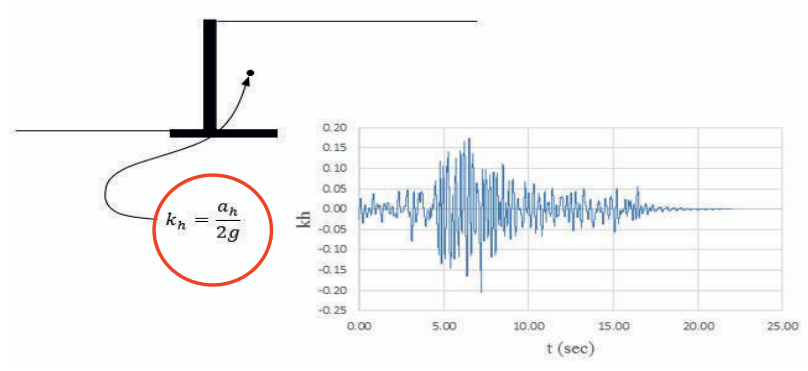

Figure 7. Coefficient of earthquake horizontal acceleration $\left(\mathrm{k}_{\mathrm{h}}\right)$ at the middle of backfill soil above the heel 
The lateral pressure coefficient of soil corresponding to the maximum and minimum points of horizontal acceleration coefficient of earthquake were calculated for both dry and unsaturated conditions. These coefficients are smaller in unsaturated condition as compared to dry condition (Figures 8 and 9). Also by comparing these coefficients to the results from Mononobe-Okabe, we can see again that the lateral active earth pressure coefficient for unsaturated soil condition is somehow smaller than those predicted using Mononobe-Okabe equation. In these figures, KAE denotes active each pressure coefficient, and KPE stands for the passive seismic earth pressure coefficient.

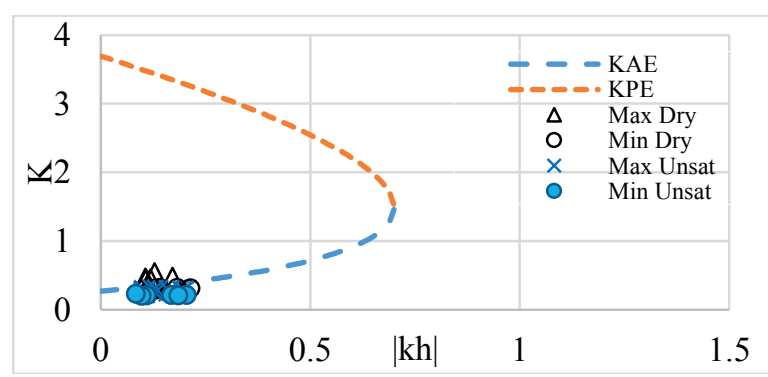

Figure 8. Comparison of horizontal pressure coefficients of soil in dry and unsaturated conditions and the values of MononobeOkabe (wall of 5-meter height)



Figure 9. Comparison of horizontal pressure coefficients of soil in dry and unsaturated conditions and the values of MononobeOkabe method (wall of 6-meter height)

\section{Summary and conclusion}

The main results of this study can be summarized as follows:

1. The maximum resultant force in unsaturated condition is smaller and the application point is located lower than the dry condition. Hence, it results in smaller overturning moment and increased stability for the wall.

2. The increase in effective stress from suction in unsaturated region results in an increase in the shear modulus proportional to the change in effective stress.

3. As expected, soil suction increases the shear strength significantly, resulting in smaller lateral force on the wall during earthquake.

4. The lateral pressures calculated from the numerical simulation indicate that the lateral active earth pressure coefficient is somehow smaller than those predicted using MononobeOkabe equation which shows that this theory is on the safe side for calculating dynamic forces behind the wall, resulted by earthquake in unsaturated condition.

5. As it was expected, the resultant force appears at an elevation above $\mathrm{H} / 3$ in dry condition. However, the results of this study for unsaturated soil condition indicate that application point of the resultant force is at an elevation below $\mathrm{H} / 3$ measured from the wall heel.

\section{Acknowledgement}

The authors wish to thank R. Behzadpour, Ph.D. student, Department of Civil and Environmental Engineering, Washington State University, USA, for his valuable comments on the manuscript.

\section{References}

1.S. A. Stanier, A. Tarantino, Active earth force in 'cohesionless' unsaturated soils using bound theorems of plasticity. Proc. of $5^{\text {th }}$ Int. conf. on Unsaturated Soils, Barcelona, 1081-1086 (2010).

2. T. Vo, A. R. Russell, Slip line theory applied to a retaining wall-unsaturated soil interaction problem. Computers and Geotechnics, 55, 416-428 (2013).

3. FLAC2d/User's manual, Fifth Edition (FLAC Version 7.0), Itasca Consulting Group Inc., USA, September (2011)

4. S. L. Kramer, Geotechnical Earthquake Engineering, Prentice Hall, Inc. (1996).

5. E. Nikooee, G. Habibagahi, S. M. Hassanizadeh, A. Ghahramani, Effective stress in unsaturated soils: A thermodynamic approach based on the interfacial energy and hydromechanical coupling. Transport in porous media, 96(2), 369-396 (2013).

6. J. M. Pereira, O. Coussy, E. E. Alonso, J. Vaunt, S. Olivella, Is the degree of saturation a good candidate for Bishop's X parameter? Proceedings of the $5^{\text {th }}$ International Conference on Unsaturated Soils 2. DOI: 10.1201/b10526-141 (2010).

7. N. Lu, J. W. Godt, D. T. Wu, A closed-form equation for effective stress in unsaturated soil. Water Resources Research, 46(5), (2010).

8. S. Oh, N. Lu, Uniqueness of the suction stress characteristic curve under different confining stress conditions. Vadose Zone Journal, 13(5), (2014).

9. I. Ishibashi and X. Zhang, Unified dynamic shear moduli and damping ratios of sand and clay, Soils and foundations, 33(1), 182-191 (1993).

10. R. A. Green and R. M. Ebeling Seismic Analysis of Cantilever Retaining Walls, Phase 1. ERDC/ITL TR02-3, US Army Corps of Engineers, Engineer Research and Development Center, (2002). 